e rápida propagação. Este tema tão pertinente foi moderado pelo produtor de rádio Adriano Cerqueira (RTP, Antena 1) com a participação do imunologista Miguel Castanho (IMM-UL), o bioquímico e divulgador de ciência David Marçal (FCSH-UNL), a geneticista Cecília Arraiano (ITQB-UNL) e a comunicadora Elsa Costa e Silva (CECS-UM). Este painel de oradores proporcionou um excelente e muito participado debate, com questões e comentários colocados pelos participantes. De seguida, teve lugar a Assembleia Geral da SPQ, presidida pelo Prof. Baltazar Castro.

O programa científico foi encerrado com a atribuição da Medalha Vicente de Seabra, destinada a premiar a alta qualidade, originalidade e autonomia do trabalho de investigação em Química desenvolvido em Portugal por um investigador de idade não superior a 40 anos. 0 galardoado de 2020 foi o Prof. Gonçalo Bernardes (Universidade de Lisboa, Portugal / University of Cambridge, Reino Unido) que apresentou a keynote Translational Chemical Biology: A small-molecule targeted RNA degradation approach - empowering RNA methylation analysis.

A sessão de encerramento do XXVII ENSPQ esteve a cargo do Prof. Joaquim Faria, Vice-Presidente da

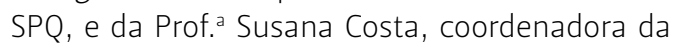
organização do Encontro, tendo sido feito o convite a todos os químicos portugueses para participar no próximo Encontro Nacional da Sociedade Portuguesa de Química, a decorrer em Aveiro em 2023.

O XXVII ENSPQ contou com o apoio institucional

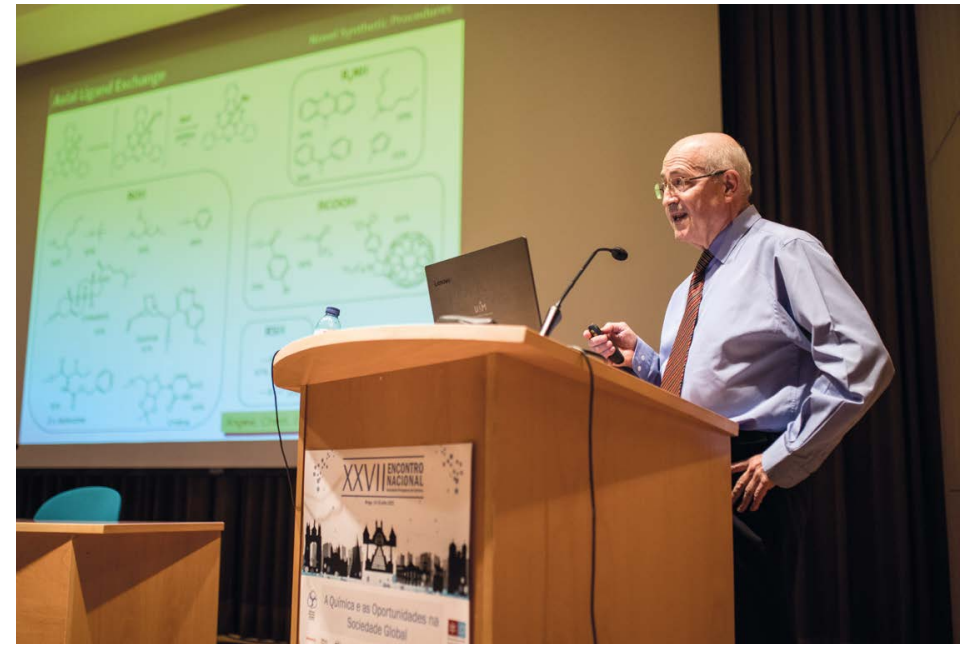

Lição plenária do Prof. Tomás Torres Cebada, Prémio Luso-Espanhol de Química 2020.

da SPQ e da Universidade do Minho, e com o patrocínio das empresas Bial, Bondalti, Bruker, Hovione, Grupo I.L.C., Izasa Scientific, Norleq, ThermoUnicam, Qlabo e Rotoquimica.

Mais informações sobre o Encontro e o livro de resumos completo pode ser consultado em xxviienspq.events.chemistry.pt.

\section{Susana Costa}

spc@quimica.uminho.pt

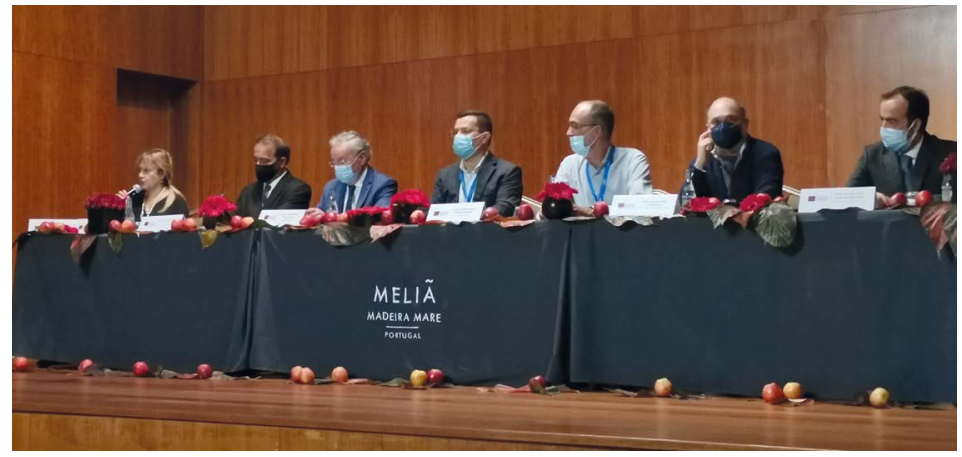

Mesa da sessão de abertura.

Entre os dias 5 e 8 de setembro de 2021, decorreu no Funchal (Ilha da Madeira), em formato híbrido, o XV Encontro de Química dos Alimentos (XV EQA) organizado pelo Grupo de Química dos Alimentos da Sociedade Portuguesa de Química (SPQ) com a colaboração conjunta do Centro de Química da Madeira (CQM) e Universidade da Madeira (UMa), tendo como

\section{Encontro de Química dos Alimentos}

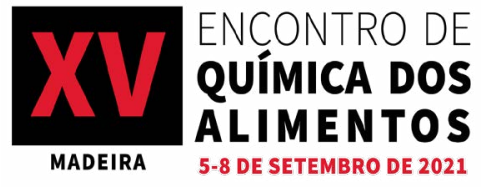

Chairman o Prof. José S. Câmara, Presidente do Grupo de Química dos Alimentos da SPQ desde 2018.

Com o tema central Estratégias para a excelência, autenticidade, segurança e sustentabilidade alimentar, participaram 275 congressistas dos quais 160 presencialmente e 115 de forma remota, via online. Foram submetidos 293 resumos dos quais 56 foram 
selecionados para comunicação oral, 24 para comunicação oral curta e os restantes foram apresentados na forma de comunicação em painel. A componente científica do congresso integrou ainda cinco lições plenárias e seis keynotes, proferidas por cientistas de renome internacional na área da ciência dos alimentos e da química alimentar, com lições que elevaram o nível científico deste evento ao patamar da excelência. Os trabalhos apresentados pelos congressistas demonstram a elevada qualidade e excelência da ciência que se faz em Portugal na área dos alimentos. As temáticas abordadas e discutidas no encontro passaram pelas tecnologias inovadoras para a rastreabilidade da origem dos alimentos, pelas técnicas espectroscópicas para a rastreabilidade e autenticação, pelas oportunidades e desafios da presença de carboidratos nos alimentos, pelas estratégias criativas para uma alimentação saudável e sustentável, pela importância dos biossensores na área alimentar, pela compreensão dos mecanismos de perceção do sabor, pelos desafios da sustentabilidade no setor alimentar e pela exploração de nutrientes naturais com potencial aplicação em produtos alimentares com propriedades antioxidantes, antidiabéticas e hipotensivas. Estratégias alternativas inovadoras e potenciais aplicações para a valorização e aproveitamento dos subprodutos agroalimentares e da indústria alimentar como forma de potenciar a sustentabilidade da cadeia alimentar, desde o campo até ao consumidor, numa base de economia circular, constituíram igualmente temáticas de grande interesse. Sendo o congresso científico nacional mais importante na apresentação de resultados da investigação nas áreas da ciência e da química dos alimentos dos diversos grupos nacionais e internacionais de universidades, politécnicos, laboratórios de Estado e afins, mas também de grupos de R\&D\&I de empresas ligadas ao sector, contou com a participação de cientistas de renome internacional na área dos alimentos, industriais e empresas do sector alimentar, representantes de agências nacionais e internacionais, autoridades de controle, laboratórios governamentais e comerciais, entre outros. Constituiu, deste modo, uma oportunidade única e privilegiada para as entidades empresariais do sector alimentar nacional, da restauração e afins, estreitarem relações e estabelecerem contactos e parcerias com investigadores, com vista ao desenvolvimento de sinergias conducentes à excelência e sustentabilidade dos alimentos e do sector.

Ao realizar-se na forma híbrida, o XV EQA contribuiu para o novo paradigma dos congressos científicos no contexto da pandemia da COVID-19, tornando-os mais desafiantes, mais trabalhosos e, simultaneamente, mais abrangentes, alargando a oportunidade de participação a muitos que de outra forma não seria possível. A cerimónia de abertura contou com a presença do

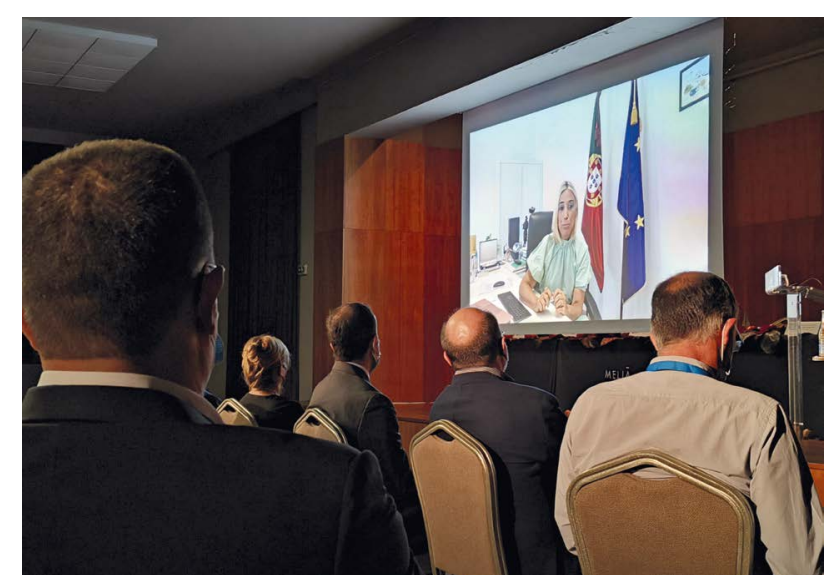

Mensagem da Exma. Sr. ${ }^{a}$ Secretária de Estado da Valorização do Interior, Prof. ${ }^{a}$ Dr. ${ }^{a}$ Isabel Ferreira.

Exmo. Sr. Reitor da Universidade da Madeira, Prof. Dr. José Sílvio Fernandes, Eng. António Paulo Santos, Diretor Regional de Agricultura e Desenvolvimento Rural, Dr. ${ }^{a}$ Madalena Nunes, vereadora da Câmara Municipal do Funchal, Prof. Dr. José Manuel Batista, Presidente da Faculdade de Ciências Exatas e Engenharia da UMa e Prof. Dr. João Manuel Rodrigues, Coordenador Científico do Centro de Química da Madeira (CQM). Os conferencistas tiveram oportunidade ainda de ouvir uma mensagem, via online, da Exma. Sr. ${ }^{\text {Secretária de }}$ Estado da Valorização do Interior Prof. a Dr. Isabel Ferreira, investigadora de excelência na área agroalimentar. $\mathrm{Na}$ cerimónia de encerramento foram anunciados os prémios para melhor comunicação oral (dois) e em painel (três). Os prémios de melhor comunicação oral foram atribuídos a Joana Lopes da Universidade de Aveiro com a comunicação Protein-rich locust bean gum industry byproduct for biobased plastics development (prémio patrocinado pela ReadyToPub) e Rita Beltrão Martins, doutoranda da UTAD-ISA, com a comunicação Apple flour from Malus domestica Borkh cv. Bravo as sustainable sweetener and texture improver in sweet gluten free bread (prémio patrocinado pela Thermo Unicam). Os prémios de melhor comunicação em painel foram atribuídos a Bruna Moreira do CIMO, IPB, com o trabalho Exploration of pineapple bio-waste as a low-cost material for natural ingredients with health benefits for application in food industry (prémio patrocinado pela Thermo Unicam), Sara Simões do Instituto Superior de Agronomia com o trabalho Development of a fermented green tomato salad dressing (prémio patrocinado pela Thermo Unicam) e Priscilla Porto-Figueira, da Universidade da Madeira, com o trabalho Exploring the volatomic profile of different tea species. A strategy to understand its health promoting potential (prémio patrocinado pela ILC).

Foi ainda atribuída uma Menção Honrosa ao trabalho Angiotensin 1-converting enzyme (ACE) inhibition 


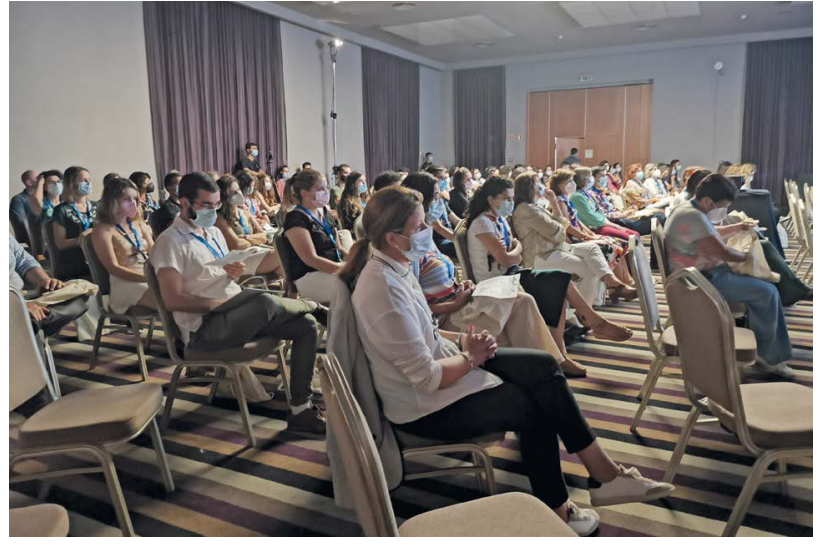

Imagem da sala durante uma sessão do Encontro.

and biological activities of different types of Azorean Camellia sinensis tea samples, em homenagem ao Prof. Dr. José Baptista, da Universidade dos Açores, como reconhecimento pelo seu trabalho de excelência na área alimentar.
O nosso agradecimento a todos os congressistas participantes, presencial ou remotamente, pelo excelente contributo para o sucesso do evento.

0 evento foi reconhecido pela European Chemical Society (EuChems) (euchems.eu) e pela Royal Society of Chemistry (RSC) (rsc.org).

Mais informações sobre o Encontro e o livro de resumos completo pode ser consultado em xveqa.events.chemistry.pt.

\section{José S. Câmara}

Chairman do XV EQA

jsc@staff.uma.pt

$>$

\section{Rosa Perestrelo}

rmp@staff.uma.pt

$>$

Jorge A. M. Pereira

jorge.pereira@staff.uma.pt

\section{Encontro de Professores de Física e Química 2021}

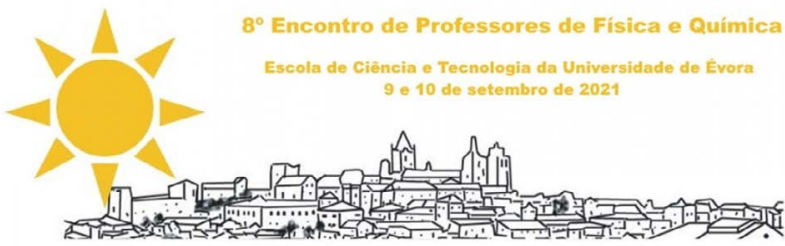

Decorreu nos dias 9 e 10 de setembro de 2021, na Escola de Ciências e Tecnologia da Universidade de Évora, o 8..$^{\circ}$ Encontro de Professores de Física e Química (8EPFQ), acreditado pelo Conselho Científico-Pedagógico da Formação Contínua como Ação de Formação para Professores do 3. ${ }^{\circ}$ ciclo do Ensino Básico e do Ensino Secundário.

Com organização da Delegação do Sul e llhas da Sociedade Portuguesa de Física e da Universidade de Évora, a organização do Encontro contou ainda com a parceria da Sociedade Portuguesa de Química.

Participaram no 8EPFQ 64 professores dos Ensinos Básico e Secundário, oriundos de diversas zonas do País, dois palestrantes e 22 formadores.

O Programa incluiu duas lições plenárias intituladas "Celulose, um material sustentável com aplicações que vão da eletrónica aos biossensores" e "Sim, temos de falar sobre alterações climáticas", proferidas pela Professora Doutora Elvira Fortunato e

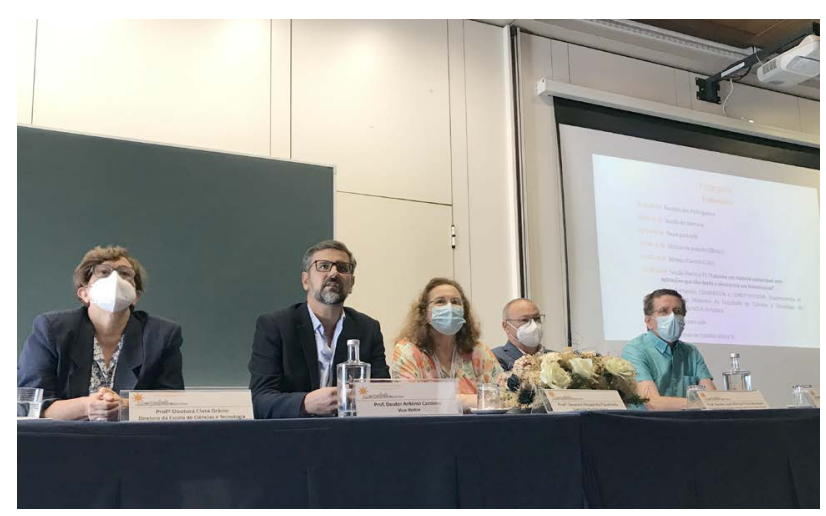

Cerimónia de abertura, que contou com a presença do Prof. ${ }^{a}$ Margarida Figueiredo (Comissão Organizadora), Prof. António Candeias (Vice-Reitor da Universidade e Évora), Prof.a Clara Grácio (Diretora da Escola Ciências e Tecnologia da Universidade de Évora), Prof. José Manuel Pires Marques (Delegação do Sul e llhas da Sociedade Portuguesa de Física) e Prof. Adelino Galvão (Sociedade Portuguesa de Química).

pelo Professor Doutor Rui Salgado, respetivamente.

Fizeram ainda parte do Programa um conjunto de 16 oficinas, de cariz marcadamente experimental e didático, muitas delas de caráter multidisciplinar, onde foram abordados temas muito diversos, tais como "Clima e alterações climáticas", "Convivendo com pinguins: histórias de cientistas na Antártida", 